\title{
Ecosystem-wide characteristics of an ESL environment in situ: An affordance-semiotics perspective
}

\begin{abstract}
Alan Wai Lun Lai
Department of Applied Psychology, Division of Science and Technology, Beijing Normal University/Hong Kong Baptist University, United International College, 28, Jinfeng Road, Tangiawan, Zhuhai, Guangdong, China
\end{abstract}

\section{Email address:}

alanlai@uic.edu.hk

\section{To cite this article:}

Alan Wai Lun Lai. Ecosystem-Wide Characteristics of an ESL Environment in Situ: An Affordance-Semiotics Perspective. International Journal of Language and Linguistics. Vol. 1, No. 4, 2013, pp. 75-89. d oi: 10.11648/j.ij11.20130104.11

\begin{abstract}
Investigating the phenomenon of how a learning environment affords opportunities for individual learners to learn has recently become an increasing interest among researchers of applied linguistics and psychology. Traditional perspective in this regard has tended to limit the phenomenon to the environment's rigid conditions and novices' controlled responses; less attention has been given to exploring the potential light that broader strategies from other academic approaches may shed upon emergent relationships between the ever-changing environment and developing actions. With this trend in mind, this paper takes an ecological model based on the theory of affordances and semiotics of signs- a scope of epistemological thinking that conceives the inquiry as a second language (L2) learning ecology or an environmental system to supporting L2 learning actions. Upon this orientation, emphasis is placed on discovering actions situated in their original context (or in situ) and then the emergence of "ecosystem-wide characteristics". By "ecosystem" it is meant that all interrelated levels of contexts are fundamental to the nature of connecting students to L2 learning. The research focused on a group of four secondary-school students in Hong Kong, in an after-school ESL (English as a second language) program over 12 lessons, examining a range of teaching-learning activities. In this paper, the ecology concerned is of informational signs interlocked for meaning-making purposes; one where signs flowed along direct and immediate perception-action heuristics for achieving L2 learning goals. Drawing upon the notion of "education-friendliness" (i.e., providing students with greater access to diverse sources of information for learning), there are implications for educational practitioners to use real-world engagement that is likely to tap students' creativity and ignite motivational sparks for using L2 to understand the world more actively and strategically.
\end{abstract}

Keywords: Ecological Perspective. Affordances, Semiotics, Second Language Learning, Situativeness, Ecosystem-Wide Characteristics, Edu-Friendliness

\section{Introduction}

In recent years, a groundswell of teaching and learning research has been seen on an environmental scale; one where individual learners actively interact with the everchanging teaching environment (e.g., Brine\& Franken, 2006; Lai, 2013;Özad \& Kutoğlu, 2004;Peng, 2011; van Lier, 2004; van Lier, 2007; Rumbaugh, 2012; Ziglari, 2012). Unlike traditional learning theory that limits emphasis to the straitjacket of stimulating or contingent events (i.e., input) that control or shape responses (i.e., output), the current orientation tends to regard learners as active actors who keep interacting with meanings potentially available or situated -in their immediate environment (van Lier, 2004; also see Rumbaugh, 2012, p. 2).

\subsection{From Input/output to "Situatedness"/characteristics}

This paper adheres to van Lier's (2004) and Garner's (2004) emphasis on "situatedness" or situating actions in original context (or in situ), i.e., how relationships in their original context are both situative and situated in a nature (or non-experimental) environment (see Bronfenbrenner, 1976) and from there situatedness replaces input. In this perspective, any relationships between learners and their environments are the interactions between the learners and the related community in a contextualized or meaningful way (van Lier, 2004).

Another breakaway from traditional output perspective is "ecosystem-wide" characteristics. At different but interrelated levels of learning contexts, a conceptual 
inclusion of the "ecosystem-wide" account of characteristics is crucial. "Ecosystem-wide" characteristics develop in situ (or emerge from situatedness), i.e., how relationships keep evolving into an outcome in their original context, and from there, ecosystem-wide characteristics replace output. In this domain, characteristics are what to explore or discover rather than elicit or control. As a further note, discovered characteristics refer the magnitude of situatedness to original contexts as to embrace the intricate complexity of activities and actions at different spatio-temporal dimensions (see van Lier, 2004).

This methodological anticipation is also parallel to ecological scientists' expectations when studying the ecology of a natural habitat; they expect to encounter a highly complex natural setting, filled with complex interactions between a diversity of species. The ecological complexity mainly stems from a great deal of specific evervarying behaviors, and the environments across different physical dimensions and biological timeframes (see Dodson et al., 1998).

Ecosystem-wide characteristics are also van Lier's (2004) "deep ecology" approach ${ }^{1}$ outcome, i.e., how the major and minor interrelated processes combine to produce an environment in which an emergence occurs (see p. 4). In this deep ecology approach, nothing causes nothing as the traditional learning theory, but only something emerges from somewhere (van Lier, 2004, p.196) in an unpredictable manner. Based on this theoretical conception, he further explains that a learning environment keeps evolving as a highly complex system in which a multitude of influences react to each other chaotically. Also in this chaotic phenomenon, a complex order would emerge (due to the edge of chaos $^{2}$ ) and afford learners a variety of learning opportunities for their learning skills to emerge and develop. Since it is unpredictable in terms of how or what the learners encounter, perceive or take any semiotic actions on learning, ecosystem-wide characteristic turns out to be a phenomenon of unpredictable emergence rather than a predictable output.

With the situated, deep, and complex issues in mind, this paper aims to document the ecosystem-wide characteristics of how a learning environment supported a group of second language (L2) learners to learn English as a second language (ESL) in terms of meaningful interactions occurring in a variety of original settings by adopting theoretical constructs from affordances theory - with

\footnotetext{
${ }^{1}$ Note that the focus on the details implies that the "deep" approach in van Lier's "deep ecology" refers to Larsen-Freeman's chaos/complexity theory. Analysis of details with the whole means the need to study the whole ecology or ecosystem with all the "deep" details. "Deep ecology" is thus meant in this sense (see van Lier, 2004).

${ }^{2}$ Edge of chaos has not been used by van Lier to further explain how a complex order emerges from a chaotic disorder. First coined by Langton (1990), edge of chaos refers to a point of onset in a complex system in which restructuring or reorganization would emerge when predictable conditions (or order) and unpredictable conditions (or disorder) are mixed at their greatest complexity levels.
}

semiotics of signs as its groundwork - in a fresh light.

To work towards this aim, the center of attention is tied to the methodologies of examining the learners' perception and action in a podcasting project, whereby they are described in terms of how they perceived, picked up and acted on topic-related information, and simultaneously how the immediate environment supported their actions ${ }^{3}$. As a result, this descriptive perception-action approach (used to specify ecosystem-wide characteristics) provides insights into a perception-action interface for promoting learners' capacity to participate and act more actively.

\section{Affordances and Semiotics}

Affordance is originally a term coined by Gibson (1979) to denote an actor-environment phenomenon in which the actor's perceptual system is related to the environment's informational sources. To the actor, there may or may not be some meaningful information from the environment for the actor to pick up for further actions. And to the environment, the actor may or may not encounter some sources of meaningful information when the actor is moving and perceiving the ambience of information. Whether an affordance takes place depends very much on the availability of information in the environment and who or what the actors are focusing on (Gibson, 1979; Reed, 1996). Meaningful information available in the environment is meant by Gibson (1979) to refer to the specifications of some invariant properties inherent in some sources of the environment that may afford certain actions to possibly occur. When some actions are afforded, they may lead to a positive or negative outcome. For example, water affords "floatability" for an organism to float on the water if the organism manages to do so, but it would also afford "drownability" to drown an organism. But whether drownability or floatability, tied to information specified by the properties of water, could be denoted as affordance is a controversial debate. In the past three decades in the community of theorists regarding the definition of the term (see Jones, 2003; Sahin, et al., 2006), theorists from many different disciplines, such as ecological psychology (e.g., Stoffregen, 2003; Turvey, 1992), product design (e.g., You\& Chen, 2002), computer science (e.g., Norman, 1988), robot-making technology (i.e., robotics) and artificial intelligence (e.g., Rome et al., 2006), applied linguistics (e.g., Nguyen\& Kellogg, 2005) and education (e.g., Greeno, 1994), have been contributing many arguments to the debate. Sahin et al. (2006) conclude that none of the

\footnotetext{
${ }^{3}$ It is recognized that ESL specific issues of acquisition are of paramount importance. However, this paper is situated in a broader sense that bears on what happens to learners' task-related actions (i.e., including but not limited to ESL learning actions) and how the immediate environment corresponds to supporting the actions. Fully accounting for all the ESL specific issues is beyond the scope of this article, except for how broader contexts (i.e., ecosystem-wide characteristics) are unraveled with students and in their goal-oriented work with each other in the L2 ecology.
} 
scholars mentioned above articulate a concrete definition of affordances.

However, Chemero (2006) indicates that studying affordances in terms of semiotics, semantic information or representations of signs in an immediate setting to an individual agent is "a good candidate" (see p. 84-85) since this way of studying allows us to understand the meaningmaking relationships between the individual agent and the meaning potential situated in the immediate environment. Also, this echoes Bronfenbrenner's (1999) biological model of human development:

In order to develop - intellectually, emotionally, socially, and morally - a human being, whether child or adult, requires the same thing: active participation in progressively more complex, reciprocal interaction with persons, objects, and symbols in the individual's immediate environment. (p. 4)

Along with this line of reasoning, a semiotic proposition of affordance is described in the next section.

\subsection{The Semiotic Proposition of Affordances}

Regarding my semiotic proposition of affordances, perception of information points towards an individual actor's perception of sign-using. In this sense, perceiving information means perceiving its signs that are symbolic, indexical or iconic. The representations of signs refer to the interpretant of a sign which, taken with respect to the actor, depends on the contexts from situation to situation. Immediate sign-using by the actor happens when an object, a tool or artefact in the environment is picked up. However, perception never ceases when a sign is picked up and used for meaning-making during an activity since perception and action are not two separate mechanisms. This point about there being no separation between perception and action is stressed by Rizzo (2006) and Sahin et al. (2006). First, Rizzo points out that action can never be separated from the ongoing perception of information. Second, the ongoing detection of information makes any given activity possible (also see Gibson \&Pick, 2000).

Similar to Rizzo, Sahin et al. provide a neurobiological basis for the direct link between perception and action - our brain's motor neurons fire not just when a motor action is triggered but also when an action by someone else is perceived. Not only that, motor neurons also fire when an agent is simply perceiving a meaning-affording object. Based on the neurobiological results, they suggest that "there is a strong link between perception and action in terms of neuropsychological activity" (p. 6). All in all, this link leads to my proposition of affordances in terms of van Lier's (2004) eco-semiotic approach:

An affordance is an immediate fit or opportunity of a meaning-making, goal-oriented activity (for good or for bad) between an active observing actor's direct perception of meaning-affording representations of signs (information) from an environmental source and the immediate signusing actions of the observing actor.

This proposition relating sign to affordance is important since it provides this paper with the semiotic basis of my affordance-based theoretical approach which is described in the ensuing section.

\subsection{The Semiotic Basis of Affordances}

According to van Lier (2004), Peirce's semiotic science of signs is the basis of all meaning potential the environment could possibly afford an organism to sense, perceive, pick up and act on. For meaning-making, an individual actor needs to be able to pick up some information, if available, in the environment. What the actor picks up therefore is not just information, but potentially, signs that are somewhere of three semiotic qualities: iconic, symbolic and indexical. But how to identify the different semiotic qualities of information for meaning-making?

Here I present an imaginary example that may shed light on this methodological concern:

1. Father: Honey, "Shao Shui Po" is here now!

2. Child: "Shao Shui Po"? What is it?

3. Mother: Ok, I am going to kitchen now! Wait!

(Mother takes out some leftover food from kitchen and gives it to an old lady.)

4. Mother: This is best for pigs.

5. The old lady: "Oh yes, we need more "Shao Shui" like this please. Thank you so much. See you next week."

(One week later, the old lady comes again.)

6. Father: "Shao Shui Po" is here now!

7. Child: "Mom, can I go? I know what to do. Please let me do it!"

8. Mother: Alright, you go then.

(As expected, the child takes out some leftover food from kitchen and gives it to the old lady.)

Based on this hypothetical situation, the child encounters three types of semiotic signs. The expression of "Shao Shui Po" in line 1 is symbolic since it represents a conventional meaning. In line 4 , the word "This" in the expression of "This is best for pigs" is an indexical sign since it refers indicationally or directly to the leftover food that the old lady collects to feed pigs. In line 5, "like this" in the old lady's expression of "we need more "Shao Shui' like this please" is an iconic sign since it denotes the resemblance of the original quality of "Shao Shui" the old lady is trying to refer to. Over time, the child manages to pick up the meaning of "Shao Shui" and from there takes further meaning-making actions more possibly.

Like this example, meaning-making actions could be contextualized in terms of semiotic signs. In this sense, the more the social and individual actions are described in terms of cultural icons, indexical signs and symbolic meanings, the more they are contextualized. In this paper, signs are the most fundamental unit of context. 


\section{Focal Activity, Participants and the Learning Environment Concerned}

The current study can be considered a revisit to the data sets originally derived from Lai (2013). In the previous study, I attempted to examine the data from an activity theory perspective while this study fundamentally looks at the data with a whole new light. Based on an affordances perspective, the research objective of the current study is to uncover the ecosystem-wide characteristics that emerged from situatedness over time in a home environment ${ }^{4}$ as part of an English language program which had been in operation for five years before the study began. In this program, four 13-year-old children joined as participants. In this study, the students (i.e., the participants) were situated differently from traditional L2 learning studies set in regular day-time school classrooms, in that the pedagogical activities occurred in a home-situated environment after regular school time. Further, the homesetting ecosystem was free from school rules, mandatory curricula and staff politics which would oftentimes serve as a complementary and alternative learning environment to the current ecology of mainstream schooling. In this way, the research could focus on situatedness in L2 context particularly responsive to individual differences among the students.

In overview, each lesson was two hours long. The entire program lasted for 12 weeks. Participant observation, video recording, and notes taken during and after class were the data collection methods employed. Data were then analyzed using an open coding scheme with emergent themes which are introduced in the next section.

Throughout the 12 lessons, the four students participated in three L2 learning activities included newspaper article sharing, English language movie watching, and two podcast talk shows (under the topics of fusion energy and real supernatural stories).However, the podcast talk show (under the topic of real supernatural stories) was the only yet intensely focal activity in this paper while others have been studied systematically in the counterpart study (i.e., Lai, 2013). Further details of this focal activity will be introduced in the next section.

\subsection{Podcast Talk Show}

Using the technology of podcast and the Internet, an activity emerged during the 12 lessons. The goal of this activity was to produce two podcast talk shows under two different topics determined by the students (see Table 1).

Table 1: Topics and content of two podcast talk shows

\begin{tabular}{lll}
\hline Episode & Topics & Content \\
\hline 1 & Fusion Power & $\begin{array}{l}\text { Scientific information about fusion energy } \\
\text { Supernatural } \\
\text { Some stories of supernatural experiences } \\
\text { claimed to be true }\end{array}$ \\
\hline
\end{tabular}

A trial episode was produced in the first lesson while two formal ones were produced in the ninth and twelfth lessons. The trial episode was not sophisticated to produce since it did not require the students to do any outside research about the topic (it was simply about our past experiences in the English learning program).But the topics of episodes 1 and 2 required the students to spend hours of research across lessons using two computers and the Internet. The more specific aim of this preparation work was to get the students familiar with the topic so that they could take up an expert-like role for the talk shows. To help consolidate and internalize information collected, the students took the initiative to integrate all relevant information by producing three sets of preparation notes. The first set contained an outline of what questions and what points to talk about during the first episode. The second one contained information about fusion power. Using their own words, the students adopted a point form style to restructure the information they obtained. They also constructed some questions to remind them what they could talk about during the talk show. The third one was also a collective work of the students who kept ten stories of supernatural experiences they found on the Internet for the second episode.

After recording each of the talk shows, they uploaded a digital file of the recorded episode to a podcast website for podcasting. For this follow-up work, the students' expertise was drawn upon since it involved a lot of technical set-ups that were beyond my knowledge. Especially for trial episode, we believed it would be easy to upload the file for podcasting; however, it turned out that they needed to spend some quality time to go through many technical rules. The successful upload at last was a milestone to the activity since it boosted the meaningfulness of this talk show activity that their talk show productions could be accessed to download and be listened to by anyone, anywhere and at anytime through the technology of the World Wide Web.

Upon the preparation, production and post-episode work, the pedagogical aim of creating a real-world environment in which the students would have a chance, at one end, to encounter, to perceive and to internalize real-life information and, at the other end, to externalize their linguistic understanding, was realized.

\section{Methodology}

To show how analysis explored data from an affordancesemiotics perspective, Table 2 specifies five investigation areas and objectives for this purpose in terms of their corresponding issues to derive for further investigation.

Note that the investigation areas and objectives developed in situ during the analytical stage after data collection. It therefore followed the same fashion of "relationships developing in situ" principle.

${ }^{4}$ This environment belonged to my twin students' home apartment located in a high-rise building in Hong Kong. 
Table 2:Investigation areas of objectives

\begin{tabular}{|c|c|c|}
\hline $\begin{array}{l}\text { Investigation areas } \\
\text { (The dynamic relations } \\
\text { of the ecology) } \\
\end{array}$ & Investigation objectives & Derived issues for further investigation \\
\hline 1. Perception of signs & $\begin{array}{l}\text { To investigate how the students perceived signs (e.g., stories } \\
\text { noticed) for semiosis in a complex activity-bound } \\
\text { environment. (e.g., an on-line website). }\end{array}$ & $\begin{array}{l}\text { - } \quad \text { Direct and immediate perception of signs. } \\
\text { Exploratory and observational behaviors in terms of the } \\
\text { students' perceptual system. }\end{array}$ \\
\hline 2. Pick-up of signs & $\begin{array}{l}\text { To study how signs were picked up in an object-oriented } \\
\text { activity (e.g., to require students to look for a particular kind } \\
\text { of information for discussion). }\end{array}$ & $\begin{array}{l}\text { - Selective and meaningful pick-up based on activity } \\
\text { objects. }\end{array}$ \\
\hline 3. Actions to act on signs & $\begin{array}{l}\text { To uncover how actions (e.g., acting on information } \\
\text { perceived meaningfully) were promoted for semiosis. }\end{array}$ & $\begin{array}{l}\text { - } \quad \text { Perceptual flexibility to perceive information and } \\
\text { encounter affordances for semiotic development. }\end{array}$ \\
\hline $\begin{array}{l}\text { 4. The interrelationships of } \\
\text { signs, actions and semiosis }\end{array}$ & $\begin{array}{l}\text { To reveal whether and how the subsets of object-oriented } \\
\text { signs, activity-based actions, and meaning-making were } \\
\text { systematically related to each other. }\end{array}$ & $\begin{array}{l}\text { The ecology as a unitary system to promote semiotic } \\
\text { actions at different dimensions. }\end{array}$ \\
\hline $\begin{array}{l}\text { 5. Internalization and } \\
\text { externalization of signs }\end{array}$ & $\begin{array}{l}\text { To find out how the students understood information and } \\
\text { made meanings (e.g., strategic production of meaningful } \\
\text { speech acts). That is to demonstrate how students' L2 } \\
\text { learning develops }\end{array}$ & $\begin{array}{l}\text { Intra-individual actions the students used to handle } \\
\text { informational complexity, to relate information to L2 } \\
\text { learning, and to make meaning more meaningfully. } \\
\text { Inter-individual actions the students used to promote } \\
\text { understanding and transform it into activity-related } \\
\text { speech acts. }\end{array}$ \\
\hline
\end{tabular}

To systematically contextualize the ecosystem concerned, five stages of methodological procedures were developed to drive the study forward:

Stage 1: To transform all raw data collected into an organized set of chronological details.

Stage 2: $\quad$ To identify complexes of signs based on the above four investigation areas and objectives.

Stage 3: To contextualize the distributed activity signs with an open coding scheme.

Stage 4: To describe the relationships (i.e., situatedness) of results obtained from stages 2 and 3.

Section 4.1 will introduce the theoretical ground for the open-coding and emerging theme scheme embedded in the above stages of analysis. What needs to continue in this section is to elaborate how the four stages work together.

To explain the first stage, the raw data of video collected during a lesson were transformed into a set of chronological details in prose. The second stage was to sort out particular details in terms of indexical, iconic or symbolic signs and to label them accordingly based on the five investigation areas (i.e., perception of signs, pick-up of signs, actions to act on signs, interrelationships of signs, actions and semiosis and internalization and externalization of signs). The third stage was to relate the labeled signs to an emergent relation of the ecology based on an open coding scheme. As an additional note, this stage gave rise to another four new dynamic relations of semiotics of the ecosystem concerned: direct perception of signs (DP-S), pick-up of signs (PP-S), actions to act on the signs (ACT-S) and affordances of signs (AFF-S).

Stage 4 is the most complex phase for analysis since new dynamic relations of semiotics kept emerging in situ when trying to relate the dynamic relations derived from stages 2 and 3. During this stage, new themes emerged to keep opening up a new area of investigation for study.
Notably, stage 1 was designed to document settings and chronological time order as the transformation scales, while stages 2 to 4 were to transform results into a set of ecosystem-wide account of the ecology concerned. The next section will continue to introduce what strategies were adopted to ensure that stage 4 underwent with the "relationships developing in situ "principle.

\subsection{Data Analysis: The Emergent Themes and Open Coding}

In the previous section, four methodological stages were listed. This section further describes these procedures and notes how the procedures of emergent themes and open coding function for data analysis.

Contextualizationis the underpinning notion and central work of this ecosystem-wide study emphasizing on situatedness and characteristics (rather than the traditional learning assumption of input and output). To accomplish this satisfactorily requires a context to be categorized. However, categorizing a context with predetermined objectives of the above five investigative areas for data collection or analysis would prevent emergent themes from emerging in situ. Brine and Franken (2006) and Buell (2002) provide a workable solution to attend to this paradoxical concern: contextualization can be done following an emic (i.e., discovery-oriented) approach by employing the emergent objectives "that emerge from the practices of the participants rather than from those that the framework [i.e., investigative areas] imposes"(Brine \& Franken 2006, p. 30).

Therefore, what was done was not to use the investigative areas for data interpretation while the heuristic objectives were used as a guideline for systematic contextualization of the practices of the participants. In this way, emergent themes were not arbitrarily enacted in front of the backdrop of the predetermined objectives of any investigative area. For example, the investigation area of 
internalization and externalization of signs did not emerge until the students' actions were subcategorized as "intraindividual" and "inter-individual".

\section{Results and Discussion}

In this section, I attempt to unveil and discuss the semiotic relationships between signs and each individual's language learning dynamism and from there a finalized ecosystem-wide account describing the ecology concerned will be presented in the next section.

\subsection{Direct and Immediate Perception of Ambient Signs}

Everyone in the ecosystem was surrounded by a semiotic ambience. As such, one striking question that emerged during the last stage of analysis is this: how could each individual student end up attaining an adaptive fit between themselves and the environment?

To respond to this question, "student-environment fit", a result drawn from each student's perceptual system and its situated actions to take (i.e., perception-action), came to the foreground. Let's take one of the students, Austin, as an example. His preparation work for a podcast talk show demonstrates the importance of the pivotal fit between him and the virtual environment. In one task that required Austin to look for some stories and background music for the talk show, he situated himself in the Internet space, surfed from website to website, went through a myriad of stories from webpage to webpage, and searched for background music song by song. Drawing from the stories and songs he encountered, Austin wondered which ones were suitable. For the background music, he could not find any he liked until he listened to the fifth song he encountered. The song was chosen since the tune was indicationally related to the theme of the talk show topic; i.e., one that intrinsically relate people to the theme. And for the story, he kept on detecting various sets of textual information (i.e., key words) found available in some websites. Finally, the story he picked up at last carried some aim-related (or topic-related) information that represented symbolically (i.e., conventionally considered to be believable) a real supernatural phenomenon. Beyond whether the information was indexical or symbolic, the aim-related information signified by the signs afforded Austin's goal-oriented actions at a perception-action level as the "student-environment fit" (i.e., to listen, to keep on detecting and to pick up).

To extend the findings further, Austin's exploratory actions were found direct and immediate. First, he perceived the songs and stories directly without any other things to mediate. For example, he heard the background music directly available from a website once he clicked on the link of the song provided on the website. This audio detection was also so immediate that he simply did not rely on listening to anything else or recalling any information. Similarly, he detected a list of titles of some potential stories; this perceptual detection was immediate and direct, enabling him to pick and choose anyone he wanted. As a result, while Austin's exploratory actions, detection and perception were situated in the background context, all the signs that carried some aim-related information afforded him the opportunity to develop a direct and immediate fit between himself and the cyberspace.

Other than Austin, another student, Justin, offered further details that may support the existence of studentenvironment fit being direct and immediate. For example, in one lesson Justin looked for some suitable stories in the format of video clips provided by some websites. Like Austin, he first detected the titles of the video clips as indexical signs that somehow pointed him directly to some suitable stories. In this context, these signs were situated as a fit that was perceived by him directly, not by the content of the video clips, but by some potential meanings provided by the titles. The opportunity to preview these potential meanings gave him a sense of which clips he should take further actions on. In one instance, one title called "The Night I Started to Believe" conveyed to Justin some indexical information that this story would potentially point him to match the object of the activity, and from this moment he went on to read it and finally picked it up as one of the stories to tell. This indexical sign (i.e., the perceived title) therefore became the direct and immediate fit between him and the cyberspace.

To discuss, the student-environment fit seemed to have an economical factor. Another student, Francis, illustrates one example. Sharing the same object with Austin and Justin, Francis did not find himself some good stories directly. But that does not mean that his perception was indirect. Instead, he observed other students' exploratory actions situated in the immediate environment as some signs so as to search for some potentially useful information and then imitated what other students were doing. For instance, in the search for supernatural stories, Francis first perceived Austin's search on some textual information and he went to the same website as Austin. This perception-action heuristic had an advantage in that it was economical and efficient since Francis was able to locate some potentially good sources of information without spending much time on the search. Also, it appeared to be an intelligent strategy when he learned from observing the consequent effects that Austin could identify from the website. In this way, he took on this perceptual dynamism and managed to focus more on the effort of determining which stories he encountered were topicrelated and which were not. Not only that, he could also bring up the quality of the entire activity to a greater extent by spending time on providing some feedback on Austin's stories.

Gibson and Pick (2000) assert that exploratory activities and observation of consequences exist in the development of an infant's perceptual systems. Based on the above results, I would add that the use of exploratory behaviors and observation skills continues to develop in young 
teenagers ${ }^{5}$, and a mastery of this exploratory system is possibly attained when teenage learners manage to connect signs they have already picked up to a shared or collective object of an activity. For example, if the students of my study were not able to act for the purpose of producing a podcast talk show, they would probably not want to spend time on the search. And even when they were aware of the object, they might not find their perceptual system in any meaningful use if the signs they explored did not match their common objects. I would further add that young children normally would not stop developing their perceptual systems, especially when they are allowed to use their perceptual systems more and more creatively for a more and more demanding object or activity. If this perspective holds true, children should be given as many opportunities as possible to develop their exploratory and observation skills since it would help them fit their perceptual skills to a semiotic goal.

To discuss further, the direct and immediate perceptionaction perspective, in the context of student-environment fit may stimulate additional thinking to assert that the signs that people act on to make meaning-making activities possible can be studied independently from cognitive representations. If information is abundantly available in the immediate setting to an individual learner, cognitive representations or schemata would become so-rare occurrence since perception of information is "always a matter of tracking something that is present in the environment" (Chemero, 2006, p. 83), echoing Gibson's (1986) assertion to some extent that:

Perceiving is a psychosomatic act, not of the mind or the body but of a living observer. The act of picking up information... is a continuous act, an activity that is ceaseless and unbroken. (p. 240)

However, the significance of cognitive representation should not be masked. At least, the current paper fails to provide any findings that could disregard the existence of schemata. The presence of student-environment fit does not imply the absence of working memory and cognitive representation for learning.

\subsection{Signs Pick-up}

In this section, I will continue to describe how signs were selectively or meaningfully picked up by an individual student to fit a specific object of an activity.

The specificity of sign selection was important to sustain the operation of an activity. For example, Joshua found one supernatural story that he thought was believable. His successful search was not a one-hit result. First, he detected signs and explored them one by one, in the same way as what Austin, Francis and Justin were described in the previous section. Recommended by Justin, his first perceptual search began from a Chinese-language website called "www.ghoststoryforum.com". On this website, he did

\footnotetext{
${ }^{5}$ The children/students who participated in the research of this paper were young teenagers.
}

not find anything that he believed to be truly supernatural, but he defined a selection criterion: a real supernatural story should have some evidence that could be seen. I responded to this contention that this criterion would be quite hard to attain, but Joshua insisted on looking for a sign to meet this criterion. After about eight minutes of search, he changed to another website called "www.video.google.com".On this website, Joshua picked up a video story that he believed to be truly supernatural. The evidence was that he believed what he could see on the screen. All of us also agreed that this story was very convincing.

This example illustrates that Joshua managed to pick up a sign believed to be right; one that could therefore be of some symbolic meaning to him. Theoretically, Joshua actualized his selection criterion by choosing some information to fit the object of the activity. Joshua not only detected a sign; he meaningfully and selectively picked it up, and this was followed with action on his part. In other words, his selective pick-up behavior signified a symbolic meaning-object fit which was a conscious means-to-fit-theends operation.

Gibson and Pick (2000) assert that the development of information pick-up is up to the capability level of selecting information with a certain thing's or event's superficial function. In this sense, an affordance-fit could still be realized in infants, but they are confined in what the function is available to afford the infants to interact with an invariant object since the infants would be too young to connect a symbolic meaning to a persisting object. The current study tends to support this assertion since Joshua, as shown in the example above, was able to selectively pick up information beyond the level of the conventional function or meaning of a sign and sensibly relate the object of an activity to the symbolic meaning of a sign. This, of course, requires him to be mature enough to handle abstract information, such as the object of an activity and the symbolic meaning of a sign. However, it is merely some preliminary evidence to provide and Joshua was simply not an infant. What Joshua could do does not imply that infants could not.

\subsection{Actions to Act on Signs}

As an actor picks up a sign from an ambience of signs (i.e., selection), the actor needs to act on the sign (i.e., action-taking process) before a semiotic outcome could be reached. To increase the likelihood of attaining a semiotic object of an activity, more flexible actions to perceive and act on the semiotic affordance of a sign (i.e., action promoted to act on signs) may play an important role in children's linguistic development. Some findings may show some support to this assumption.

For example, Austin's perceptual learning system was seen with its flexibility in generating semiotic actions. For example, when he was selecting the second story titled "Opening Doors", he turned to an exploratory rather than his previous strategy. The following excerpts show what 
further semiotic actions were promoted as a result of his exploratory effort.

1. Austin: "Wow, they burn down the home." What do you think? (Francis was reading besides him, but it was Austin who controlled the mouse.)

2. Francis: It is good.

3. Alan: Is it good?

4. Austin: Yes!

5. Alan: Why good?

6. Austin: Because the house is burnt down....

His rationale "Because the house is burnt down" to differentiate this story from others was that if the house was not affected by some supernatural beings, it would not have been burnt down (or someone is held responsible for burning down the house). This rationale was a vital context in the promotion of his semiotic actions on three fronts. First, Austin managed to use the expression "Because the house is burnt down" as an indexical sign to direct him to the story he believed to be truly supernatural. In other words, he was able to explore and detect some indexical signs in the context of the story. Second, he immediately acted on the affordance of this indexical sign (i.e., the rationale "Because the house is burnt down") by foregrounding the "supernatural quality" of the story (lines $5 \& 6)$. Third, the indexical sign actively engaged by Austin during the podcast activity further afforded a question-andanswer opportunity between him and another speaker (Joshua), thus contributing more relevant meanings to the entire activity context:

Alan: Any question or feedback you have about Austin's story?

Joshua: Who burnt down the house?

Austin: I don't know, but I think it was the family or friends. (He kept smiling when he spoke.)

Alan: Ok...good!

Although he was not sure, he certainly followed it up by guessing and pointed this sign to "the family or friends". His smile also indicated to me that he enjoyed this meaningful guess.

Based on the interpretation of Austin's perception-action strategies as a whole, we can see that the more flexible one's perception-action system to detect information is, the more likely one is able to encounter more affordances for semiosis. That means if Austin was merely fixed with his observation system, he might not be able to find the first story which afforded him not only some conventional information for semiosis but also the chance that he could actively act on a sign to meet the object of an activity. And if it was not his flexibility to switch to the exploratory mode, he might still not be able to find the second story, let alone the truthfulness of which he could critically base on as an indexical sign.

Looking at the above example, I tend to support the idea that flexibility to act on is needed to accomplish one's perceptual system. Also, this idea might expand Reed's (1996, p. 86-7) characterization of the human perceptual system as being only about one's exploratory action system; if not, at least flexibility to act may be considered as a subsystem of one's exploratory action system.

Gibson and Pick (2000) pointed out that flexibility of perceptual system promotes survival or the continuation of children's development. This notion is parallel to the above results that flexibility of the perceptual system not only diversifies linguistic actions but also promotes the survival (or facilitate the ongoing processes) of the podcast activity. All in all, actions to act on signs were found in this part to amplify the sign pick-up system by facilitating the actualization of the meaning-object fit, thus reinforcing the student-environment fit as well.

\subsection{Interlocking and Information Cycle}

Based on the results of the previous three sections, a consolidating argument is this: the systems of perception, signs pick-up and actions to act on signs were interlocked with each other in the ecology concerned (see Figure 1). To foreground this interlocking phenomenon of interest requires the recapturing of some interlocking backgrounds around the three subset-systems. First, the direct and immediate system of perception related each individual learner to the ambience of signs (i.e., student-environment fit), but due to the inherent complexity of the semiotic ambience in the real-world environment, the perceptual system tended to selectively pick up the signs that were object-related (i.e., meaning-object fit). Therefore, the meaning-object fit was the structural basis of the studentenvironmental fit. On top of this basis was the system of actions to act on signs that was based on the perceptual system's direct, immediate, ever-on and ever-flexible features to promote a variety of actions to act on signs for semiosis. The significance of action promotion is that it could increase the likelihood to meet the object of an activity, thus bringing the meaning-object fit and studentenvironment fit to a more object-oriented level for semiotic development.

Information flowed through the whole ecology concerned. Within the system of the three subsets, information available in the ambience of signs flowed to the system of signs pick-up through the students' individual perceptual systems that directly and immediately detected and encountered the ambient signs. Next, information continued to flow to the system of actions to act on signs through the system of signs pick-up which went on to perceive and moved on to select object-related signs from the complex, real-world environment. Information did not stop flowing at this point. But before describing how it continued its flow, we need to take the "openness mechanism" of the ecology into account as well.

The real world was in the ecology of the ultimate source of real-life information (e.g., the information providers of the Internet or the newspaper). Accessibility to the source vitally depended on the openness of the ecology. An "In" openness brought in real-life information or signs to the ecology (e.g., all the real-life stories the students looked for in the cyberspace). This "In" therefore supported the 
learning settings to become ambient of real-life signs. Situated in the real-life settings, the students' perceptual systems first came to play and information began its flow through the three interlocking subset-systems of perception and actions. Before information flowed through the "Out" openness (e.g., the podcast of the talk shows to broadcast to the rest of the world through the Internet.), it was the system of "action-transformation" or actions that acted on signs to transform the real-life signs into objected-related real-life signs through the active learner's internalization and externalization of mental understanding. This mechanism thus contributed to the production of actiontransformed information which then flowed back to the real world, fulfilling the object-oriented meaningfulness of an activity. Figure 1 illustrates the flow of information through the openness mechanisms and the three interlocking subsetsystems of perception and actions. For reference, this type of informational flow will be called an "information cycle'. This figure is best looked at first from the top-most node in the middle with the label of "The Real World". This node refers to the source of information available to sign users (or the students) within the ecosystem. The arrow connected to the node refers to the abundance or complexity of information (formed by S1, S2 and S3 or different types of information) flowing from the real world, and through the "in" openness of the ecosystem, the information continues to flow and at a certain point gets perceived by a student directly and immediately. This is a student-environmental fit as represented by the node the different kinds of information flow to. The middle-bottom node refers to "signs pick-up" or signs picked up by the same student. Here, what the student picks up from the different kinds of information depends on the objective (or the aim) of the activity (i.e., O2). This is therefore where the meaning-object fit is located. The last node, "Actions to act on signs", refers to object-oriented actions the student acts on, naturally forming action-transformed and objectrelated information. Through the "out" openness of the ecosystem, the information flows back to the real world, being part of the source of information which becomes available again for students or teachers to use for other meaning-making purposes or activities.

This unitary system may provide an insight with regard to the close relations of object-specific information, internalization and externalization of mental understanding. In this context, what are the actions to promote internalization and externalization of mental understanding? The next section will address this final issue before concluding the ecological characteristics of the ecology concerned in Section 6.

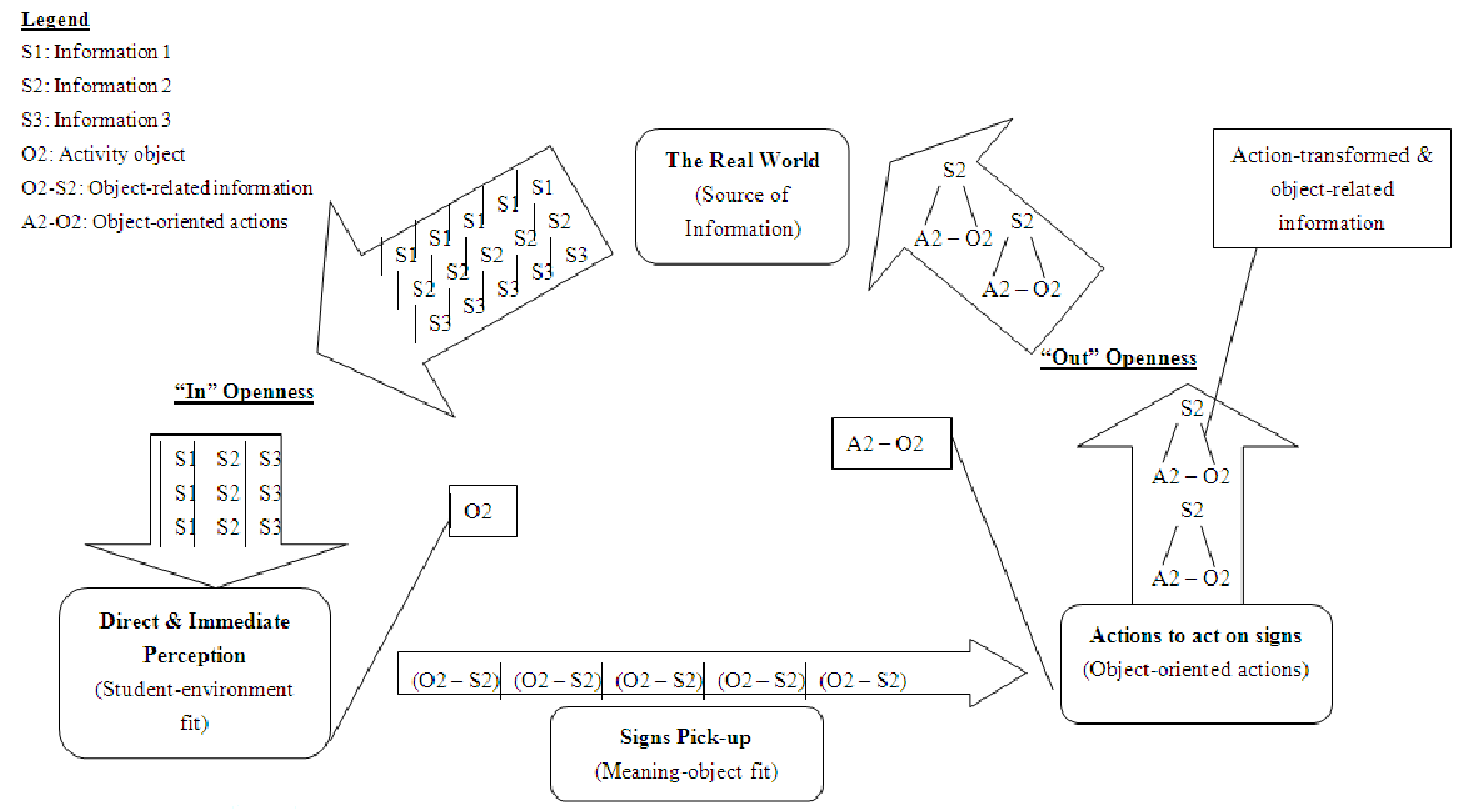

Figure 1: Information cycle

\subsection{Understanding to Internalize and Externalize through Actions}

The information cycle informs us that what signs to perceive, to pick up and to act on depends a great deal on the object of an activity each actor is tuned in to. It also shows that the system of actions to act on signs is of importance since it is the one to specifically promote semiotic actions to increase the likelihood to actualize the object of an activity. In this regard, the concern of the current study is to find out what semiotic actions were employed by the students to act on signs for meaningmaking.

Related to this concern, understanding what the actions were will actually provide a better account to inform what mechanisms were essential to help my students develop understanding in L2. It may also offer some insights for informing a long-unanswered concern raised by Reed (1996):

What kind of mechanism could cause them [children] to 
change from using words merely to indicate things into being capable of uttering genuine speech acts, containing propositional structures that are well formed according to the rules of the language? (p. 167)

In this section, related semiotic actions that work together are in nature treated either as (1) intra-individual (i.e., emerged within an individual's internalization and externalization) or (2) inter-individual (i.e., emerged individually but situated between two individuals' internalization and externalization) mechanisms. In here, internalization refers to an understanding of the external properties of an environment while externalization refers to displaying the understanding of the external properties in the environment (see Lantolf \& Thorne, 2006). The following sets of ecological details and interpretation will be presented to address Reed's concern first before fitting the two types of actions/mechanisms into the picture.

First of all, the point to address Reed's query is that internalization and externalization of understanding is the mechanism to generate genuine speech structured accordingly with appropriate grammar. How does it work exactly? Would it be related to the affordance of signs? A look into some details below may shed some light on these questions:

Austin: Ommm...this is another story about...Um... Doors Opening. Maybe you think that it is so common among fake ghost stories, but I don't think so. Hmmm... That started one night when...Um...there are children playing in a house, and suddenly the door opened. And they, they were quite sure that they locked the door, but they go and lock the door again, because they are not so sure about what they did before. And, and then after a few minutes, the door opened again and they were very scared of it and suddenly a quite shadowy figure passed the window and then...Hmmm...the children were so scared and later they searched about that and asked their parents. And one of the parents told them that there was a woman who lived with a dog hit by a car outside their house. And after that the house was haunted. And after they realized out the truth, the whole family moved away, and the house was burnt down.

Austin's speech was based on a story called "Opening Doors", originally written by Cindy from Illinois, in the US. When I compare his version with the original version as shown below, it is not hard for me to notice that Austin's speech was clearly a paraphrased or fully internalized version, all using his own words:

"Opening Doors

One night, me and my best friend Stacey were home alone and we were watching the Simpsons. We had both of my cats oreo and smokey with us. Before we made sure all the doors were shut. We were sitting there. All of a sudden we heard the door open so we got up and went to look. It was closed... Then we locked it and checked the other doors and nothing was there. We went back watching the Simpsons and heard the door open again (now remember we locked all the doors). Well the door was shut but it was unlocked. We looked out the window and saw this shadow walk by. I opened the door and yelled "anyone out there"? No one answered. So I went back to the window and saw this person that was all white, like a ghost floating in the air. I called my dad and he came home and then he told me the story that a women had got hit by a car when she was walking her dog and now she hangs out around our shed.

After I realized that out and my dad realized out the story was true, we moved right away and they burnt down the house, no one would move there because of the lady that got hit by a car walks around the shed and house" (Cindy, 2007).

There are several points worth to note regarding this generation of genuine speech acts by Austin. First, when Austin was delivering his story during the talk show, he did not rely on the preparation document. He just held a microphone and kept looking at everyone's eyes when uttering his thoughts. At times he just needed half a second to a second's pause (marked by "Ommm", "Hmmm" or "Um") for his active thinking (or/and to avoid awkwardness induced by externalization so as to bring in a smooth continuation of speech). But the most marked feature is Austin's personal opinion, well uttered before the story began: "Ohm...this is another story about...Um... Doors Opening. Maybe you think that it is so common among fake ghost stories, but I don't think so". This opening speech shows that he had internalized the whole story from the original version before he delivered it in his own words. Not only that, this opening speech also became an indexical sign pointing directly to the story he was about to deliver. In other words, he used this indexical sign to draw everyone's attention and even tried to influence his listeners' belief systems. Austin acted on these semiotic signs by transforming the entire internalized story into a meaningful opening speech (or an indexical sign) creatively in a real-life, on-air activity.

Internalization of the story and production of some genuine speech, however, was only a part of the mechanism. The rest of it was externalization of understanding. After Austin's opening speech, he managed to externalize his own words (i.e., his own mental understanding) by telling everyone what the story was about. During the externalization, he tried to deliver a genuine speech formed following the correct grammatical rules of English. In the first two sentences, he mixed up the use of present and past tense. But after the first two sentences, he cleared this mixup problem all by himself, and starting from the third story, he showed no more problems using the past tense correctly. His performance also shows that the original story afforded him the content upon which his understanding was based and externalized more economically in the real world context. For example, the original story had the line "So I went to the window and saw this person that was all white, like a ghost floating in the air". And Austin's externalized version was "...and suddenly a quite shadowy figure passed the window". Comparing these two versions demonstrates that Austin used the idea afforded by the 
original story to structure his understanding and to externalize it meaningfully in the same but a more economical manner than in the original story, using fewer words (9 words used instead of 21). Some similar findings showing more economical patterns could also be found in the next line of the original story: "I called my dad and he came home and then he told me the story that a women had got hit by a car when she was walking her dog and now she hangs out around our shed." But Austin's externalized version was a bit shorter (32 words used instead of 38 ) with similar meaning: "And one of the parents told them that there was a woman who lived with a dog was hit by a car outside their house. And after that the house was haunted." Overall, this economical pattern resulted in Austin's internalization and externalization of understanding in L2 reducing the length of the original story by $40.24 \%$ (i.e., from 230 words down to 164 words). What is the significance of this result? One possible area of significance would be that children tend to internalize the core themes or key points rather than the details. This means that they may tend to fill in a speech with contextual details and skip part of it or change the whole structure in the way they think appropriate.

In light of his following this information-managing strategy, three intra-individual semiotic actions further resulted: (1) to help reduce complex information; (2) to organize mental understanding in a way that could satisfy the object of an activity (i.e., to tell people what the speaker thinks they want/need to hear); and (3) to bring a further flexibility to one's externalization of understanding (or production of genuine speech). The next three subsections will elaborate on these three intra-individual mechanisms while the inter-individual one will be presented in the fourth one.

\subsubsection{Economical Actions Based on Complexity Management}

Gibson and Pick (2000, p. 199) indicate that "we learn to detect information that best and most economically specifies some affordance". But how do we manage to become economical in our perceptual learning? The current study seems to suggest that the object of an activity is to afford an actor opportunities to reduce complex information. For example, Austin realized that the original story could be seen as a complex set of information. Based on the information economically specified by the object of the activity, he reduced the complex information to a more manageable size. Perhaps what is equally important is that Austin's ongoing awareness of the object of the activity to share a supernatural story with everyone in a real-world talk show - developed a vital context for his internalization and externalization of understanding, and this context acted as an affordance to help him specify what information to pick and to transform in order to meet the goal of a linguistic task. Using the least information to meet the maximum demand of the object of an activity was the economical actions that characterized this complexity management system.

\subsubsection{Object-Oriented Actions Based on Organism-Environment Fit}

What is underlying this complexity management system for L2 learning should be the direct and immediate detection of linguistic information in the complex environment that best specifies the object of a linguistic activity. The reason for this argument is that the system depends very much on the availability of chances to develop a meaningful context for the learner to interact with. That means when an L2 learner increases the flexibility of his/her perception-action system, the learner would normally have more opportunities to detect more meaningful information; as more meaningful information is perceived, it is more likely the learner would encounter more information that contributes to his/her mental understanding and skills development in L2. But since more and more information picked up could become more and more complex, not all of it will lead to an affordance to emerge for further semiotic actions (or, in other words, not all information picked up is relevant to the ultimate object of an activity).

In light of the complexity of information, the complexity management system comes into play. With this system, a learner detects and uses the object of an activity as an affordance to help the learner select the least amount of information for semiosis. The more this system is in work, the more likely one would meet the object of a semiotic activity by transforming one's mental understanding into more informed or more object-oriented speech acts. Also, when more of such object-oriented, genuine speech is produced, it will increase the chance to meet the ultimate goal of a linguistic activity. This complexity management system is therefore found in this way as an essential characteristic of ecology to help an L2 learner increase the chances to reach an organism-environment fit with objectoriented actions for L2 learning.

\subsubsection{Strategic Actions Based on Behavioral Adaptation}

The complexity management system can also be described as an adaptive system. To describe it as a system to reduce complex information may overshadow its adaptive side of nature. In one perspective, this system is characterized with a range of actions to increase the likelihood of attaining a perceived object of an activity. This flexibility is adaptive since it allows a learner to take not just one but many actions (or a varied combination of them) to increase the chances of reaching a goal. For example, in the ecology under concern Austin employed five strategic actions to internalize the above-mentioned story by:

1. Skipping names.

2. Skipping some background details while the core theme remained intact.

3. Changing the wording with his own more condensed words or mental understanding.

4. Shortening or restructuring the sentences with his 
learned rules of grammar.

5. Adding pauses to maintain the flow or continuation of the externalized speech.

The above actions taken by Austin demonstrate that he was not rigidly fixed on a single way to internalize the story he perceived. Technically, he used whatever he thought appropriate to reach the semiotic goal. His chances of reaching the goal thus grew better as he used more adaptive and economical strategies to reduce complex information. More importantly, genuine speech was produced meaningfully with the least possible use of signs or information in this way. The increased likelihood of reaching is goal therefore helped him to maintain an organism-environment fit adaptively with his object-related actions for L2 learning.

After discussing how the first type of semiotic actions (i.e., intra-individual) was found to act on signs for semiosis, the second type (i.e., inter-individual) will be presented in the next section.

\subsubsection{Affordance System}

Justin began to talk about his story about a guy who saw a supernatural girl-like image somewhere in his apartment. After he finished telling the story, I asked who chose it. Austin said the story was chosen by him.

Justin's first supernatural story to tell in the last podcast talk show was originally found by Austin, his twin brother. Following the same pattern of discovery, Austin's first story was also found by Justin. The pattern of discovery was that in one lesson Justin encountered the textual story of "The Night I Started to Believe" on a website that his brother and Francis were looking at. When I asked him why he picked this story, he said: "Because it is detailed. It seems to be real. It has a description of what the ghost looks like". Managing to transform this story into some object-related information, he saved it in the preparatory word document on the computer. In the next lesson, Austin selected this story from the document and further acted on it by internalizing it since he was required to retell this story in his own words. Without depending on the notes, Austin also managed to transform this story further into some object-related, action-transformed ${ }^{6}$ information when he externalized the story in the real-life podcast platform.

The context regarding Austin's speech acts illustrates the second type of semiotic actions promoted to act on signs to make it more likely that the object of an activity would be met. Since the context was situated in an inter-individual setting (or actions emerged individually between two learners' own internalization and externalization mechanisms), this type of action was featured with the interrelations (however, not interactions) between the two individual students. It is deemed a system rather than actions executed by a single individual as intra-individual ones. This level of action-based mechanism is then called

\footnotetext{
${ }^{6}$ The information was action-transformed since the information was acted on by Austin's semiotic actions of transforming the story into his internalization and externalization of a level of individual speech acts.
}

the "affordance system".

In the affordance system, the students developed their second language by generating more object-related and more action-transformed information (i.e., $\$ 2$ and see Figure 1) in an inter-individual environment. A2 - 02

The exact theoretical mechanism of the affordance system is that when the externalized information already perceived, picked up and internalized by a student (e.g., Justin's selected story) is further perceived, picked up and internalized by another student (e.g., Austin's further speech acted on Justin's selected information), the former affords the latter object-related information for promoting further semiotic actions to act on and to transform the latter's mental understanding in L2 into some object-related and more action-transformed speech acts. Semiotic complexity could thus be increased, from one student to the next, in this inter-being perception-action relation as information flows all the way through in the L2 learning ecosystem.

As compared to the affordance system, the system of information recycling that I introduced above in Lai (2013) for the purpose of preserving useful information for semiotic survival (or preventing useful information from being forgotten and reused to make further useful meaning). Especially for object-related information, it was prevented from disappearing or getting lost in the ecosystem when it was determined by a learner to be object-related, and then further perceived and picked up for further semiotic actions to be acted on by another learner. Information preservation through the system of information recycling was, however, a side effect of the affordance system. In light of the latter system, the resulting main effect on the current ecology was that information preserved for its object-related value afforded another active learner a context so that he could develop his mental understanding of L2, during externalization, to a more situated, more contextualized or more meaningful level of speech acts.

\section{The Ecosystem-Wide Characteristics of the Ecology Concerned}

After the consistent analyses of the ecology concerned through the affordance-semiotics perspective, an ecosystem-wide account is consolidated in this section. Below is a summary provided to respond to the research question concerning the ecosystem-wide characteristics of the ecology.

Based on the analysis, the resulting understanding of the L2 home-situated program is that it was found to be an ecosystem that resulted from the interactions of informational and perceptual components. In a system-wise sense, all the components combined to interact and interrelate with one another to form a unitary whole. It was also a system constantly converting information into a variety of signs, and it thus increased in semiotic complexity over time. 
The program's ecosystem was made up of many perceptual actions interlocking to each other, information pick-up and actions to act on signs for internalization and externalization of mental understanding in L2. More precisely, signs on different intra-individual settings naturally flowed in each of the activities along the complex interactions of signs (i.e., information cycle) and semiotic, intra-individual actions coupled with inter-individual information recycling (i.e., affordance system).

Intra-individual actions included economical actions that were characterized as using the least amount of information to meet the maximum object in an ambiance of information, object-oriented actions that helped the learners to internalize complex sets of information in a more manageable manner. And of the inter-individual affordance system, individual actions were promoted to act on signs to produce more object-related, contextualized speech through internalization and externalization of mental understanding with information afforded by and from one individual student to another.

\section{Implications: Towards an Education- Friendly Environment and Pedagogy}

Situated in the semiotic ambience, each individual participant was described in terms of their dynamic relationships with the proximal contexts, utilizing the congruent ideas of Gibson's theory of ecological affordances and Peirce's semiotics. As a result, a diversity of perceptual interfaces between each student and the proximal contexts have been uncovered. In this section, some implications regarding the significance of building an education-friendly ("edu-friendly" or "edu-friendliness" for short) environment and pedagogy will be introduced with respect to its rationale and pedagogical significance.

\subsection{An edu-Friendly Environment: edu-Friendliness}

An edu-friendly environment could be characterized with a diversity of signs made ambient and easily available for L2 students. The rationale for this specification is that when signs are diversified, learners would have a greater chance to encounter more varieties of affordances for semiosis. This is important since a wider range of signs made ambient in the language-learning environment means more and greater chances for students to produce more meaningful speech in L2. Based on this argument, when designing an edu-friendly environment with signs ambient and available for easy use, the openness of the environment to sources of information, especially the real world as the vast source of information, would be essential.

Drawing on some results of this current study, the next three subsections will present three ideas for how pedagogy could be developed so as to extend the educational value of an edu-friendly environment to its greatest extent.

\subsubsection{An edu-Friendly Pedagogy I: Perception-Readiness}

An edu-friendly pedagogy may need to consider a student's perception-action system and the object of an activity in an edu-friendly environment ambient with signs. When an environment can afford students varied chances to develop their perceptual learning systems, we can expect to see an increase in the chances for students to utilize their perceptual skills with an ambience of signs. And, in this edu-friendly environment, students would be more likely to search and make use of the signs in a more meaningful manner. For example, in my study, one student used not only his observation skills but also an exploratory system to actively detect and explore various sources of signs. To work for an activity aim, he paid a great deal of attention to some specific object-oriented information and finally picked up some meaningful information that he later used to share with other students in a semiotic activity. Individual styles and strategies for learning emerge not as forced outputs but as functions of the interface between learners' perceived semiotic affordances and the environments that afford various learning possibilities. The implication is that an edu-friendly pedagogy should readily encourage, respect and result in students' individual styles of language learning. In other words, a pedagogical interface should be ready enough to develop each student's perceptual system. Placing "unfriendly" stress on the end results of speech production would probably undermine the emergence of individual styles or personalized perceptual processes in an L2 pedagogy, and perhaps lead to second language underdevelopment.

\subsubsection{An edu-Friendly Pedagogy II: Perception-Object Fitness}

Continuous awareness also helped my students single out what was needed and what was not out of the complex array of signs to which they were exposed. The implication from this set of results is that although complexity of signs can be seen as an affordance itself (since it affords students more chances to develop their complexity management system), the success of making use of the affordance for semiosis and semiotic development depends greatly on a student's conscious and ongoing perception of an activity and its object. In this sense, an edu-friendly pedagogy may need to ensure that all activities are able to afford students a very clear, invariant object, besides ambience of signs, to develop their complexity management system (i.e., their capacity to dealing with complex information more possibly).

\subsubsection{An edu-Friendly Pedagogy III: Social-Historical Interfaces}

The third point of concern related to creating an edufriendly pedagogy is how it makes the learner environment fit through adaptation over time. If perception-action flexibility is what to promote adaptation by increasing one's capacity (or strategies) to complete a particular semiotic task, more flexible actions may result in a higher level of semiotic development. Take one result as an 
example. During the 12 lessons, the students collected a diversity of points or stories, and they perceived, selected, discussed, managed, organized and at last internalized them with their own speech throughout different time periods before fitting the perceived information adaptively to the contexts during externalization. At any rate, the final externalization was a genuine speech-making process based on what they had encountered socially and historically. That means it was an adaptive fit between the students and the environment through the socio-historical interfaces over time. In this regard, if edu-friendliness is a pedagogical objective, the designer may consider interfaces that are open to information, prepared to active sharing and flexible to needs.

\section{Summary and Concluding Remarks}

The contexts of the ecosystem concerned are of the nature that L2 learning emerged from a myriad of semiotic relationships between signs and each individual learner's direct and immediate perception-action system. A breakdown of the nature, based on the theory of affordances, demonstrate show the learners related activity objects to information encountered and further transformed object-related information into their own mental understanding of L2 through internalization and externalization. To conclude, semiotic actions that emerged from the affordance-semiotics relationships characterize the students' L2 learning strategies in terms of complexity management, organism-environment fit and flexibilityadaptation maintenance.

For practice, a greater understanding of the ecology of L2 learning may lead to better teaching experience (e.g., with more appropriate use of teaching resources, better pedagogy for ESL learners or better pedagogical design for L2 education).If edu-friendliness is what to take into account in this regard, three environmental specifications including perception-readiness, perception-object fitness and social-historical interfaces may deserve some notice. More specifically, the focus needs to be on finding better ways to promote students' direct and immediate perceptual systems and increase the diversity and richness of the sources of information to which they have access. Such real-world environment engagement is likely to ignite sparks of motivation and interest on the part of students for using their L2 more actively and strategically as a means to better understand the world around them.

\section{References}

[1] Brine, J., \& Franken, M. (2006). Students' perceptions of a selected aspect of a computer mediated academic writing program: An activity theory analysis. Australasian Journal of Educational Technology, 22(1), 21-38.

[2] Bronfenbrenner, U. (1976). The experimental ecology of education. Educational Researcher, 5(9), 5-15.
[3] Bronfenbrenner, U. (1999). Growing chaos in the lives of children youth and families: How can we turn it around? Retrieved from http://parenthood.library.wisc.edu/Bronfenbrenner/Bronfenb renner.html

[4] Buell, J. G. (2002). COWS in the classroom: Technology introduction and teacher change through the lens of activity theory. Retrieved from http://www.ed.uiuc.edu/meter/Documents/COWS_FollowU p.pdf

[5] Chemero, A. (2006). Information and direct perception: a new approach. In P. Farias\& J. Queiroz (Eds.), Advanced Issues on Cognitive Science and Semiotics (pp. 75-93). Maastricht, Netherlands: Shaker.

[6] Cindy (2007). Opening doors. Your ghost stories. Retrieved from http://www.yourghoststories.com/real-ghoststory.php?story $=543$

[7] Dodson, S, I., Allen, T. F. H., Ives, A. R., Jeanne, R. L., Kitchell, J. F. Langston, N. E., \& Turner, M. G. (1998). Ecology. New York: Oxford University Press.

[8] Gibson, J. J. (1979). An ecological approach to perception. Boston: Houghton Mifflin.

[9] Gibson, J. J. (1986). The ecological approach to visual perception. Hillsdale, NJ: Lawrence Erlbaum Associates.

[10] Greeno, J. G. (1994). Gibson's affordances. Psychological Review, 101(2), 336-342.

[11] Lai, A. (2013). An Ecosystem-wide study of a complex ESL program through activity theory and semiotics. International Journal of Language and Linguistics, 1(2) 54-69.

[12] Langton, C. G. (1990). Computation at the edge of chaos: Phase transitions and emergent computation. Physica D: Nonlinear Phenomena, 42(1-3), 12-37.

[13] Garner, M. (2004). Language: An ecological view. Bern: Peter Lang.

[14] Jones, K. (2003). What is an affordance? Ecological Psychology, 15(2), 107-114.

[15] Gibson, E. J. \& Pick, A. D. (2000). An ecological approach to perceptual learning and development. New York: Oxford University Press.

[16] Lantolf, J. P., \& Thorne, S. L. (2006). Sociocultural theory and the genesis of second language development. Oxford: Oxford University Press.

[17] Nguyen, H. T., \& Kellogg, G. (2005). Emergent identities in on-line discussions for second language learning. The Canadian Modern Language Review. 62(1), 111-136.

[18] Norman, D. A. (1988). The psychology of everyday things. New York: Basic Books.

[19] Özad, B. E., \&Kutoğlu, Ü. (2004). EFL students use of technology in the presentations. The Turkish Online Journal of Educational Technology. TOJET, 3(2), Article 3. Retrieved from http://www.tojet.net/articles/v3i2/323.pdf

[20] Peng, J. E. (2011). Changes in language learning beliefs during a transition to tertiary study: The mediation of classroom affordances. System, 39, 314-324. 
[21] Reed, E. S. (1996). Encountering the world: Towards an ecological psychology. New York: Oxford University Press.

[22] Rizzo, A. (2006). The origin and design of intentional affordances. Proceedings of the 6th ACM Conference on Designing Interactive Systems, University Park, PA, USA.

[23] Rome, E., Hertzberg, J., Dorffner, G., \& Doherty, P. (2006). Towards affordance-based robot control. Dagstuhl Seminar Proceedings, Wadern, Germany. Retrieved from http://drops.dagstuhl.de/opus/volltexte/2006/725

[24] Rumbaugh, D. M., King, J. E.;Bearan, M. J., Washburn, D. A., \& Gould, K. (2012). A salience of theory of learning. Encyclopedia of the Sciences of Learning, Part 1, 1-4.

[25] Sahin, E., Cakmak, M., Dogar, M. R., Ugur, E., \&Ucoluk, G. (2006). To afford or not to afford: A new formalization of affordances towards affordance-based robot control. Middle East Technical University Technical Report, August. Retrieved from http://www.kovan.ceng.metu.edu.tr/wbt/openUploads/SahCa k_06.pdf

[26] Stoffregen, T. A. (2003). Affordances as properties of the animal-environment system. Ecological Psychology, 15(2), $115-134$.
[27] Turvey, M. T. (1992). Affordances and prospective control: an outline of the ontology. Ecological Psychology, 4(3), $173-187$.

[28] You, H. C., \& Chen, K. (2002). A comparison of affordance concepts and product semantics. Robot and Human Interactive Communication, 6th Asian Design International Conference. Retrieved from www.idemployee.id.tue.nl/g.w.m.rauterberg/conferences/CD _doNotOpen/ADC/final_paper/105.pdf

[29] vanLier, L. (2004). The ecological and semiotics of language learning: A sociocultural perspective. Dordrecht: Kluwer Academic.

[30] vanLier, L. (2007). Action-based teaching, autonomy and identity. Innovation in Language Learning and Teaching, 1 (1), 46-56.

[31] Ziglari, L. (2012). Affordance and second language learning. Encyclopedia of the Sciences of Learning, Part 1, 175-179. 